Document downloaded from:

http://hdl.handle.net/10251/50487

This paper must be cited as:

Tortosa, M.; Manjon, F. J.; Mollar, M.; et ál. (2012). ZnO-based spinels grown by electrodeposition. Journal of Physics and Chemistry of Solids. 73(9):1111-1115. doi:10.1016/j.jpcs.2012.04.002.

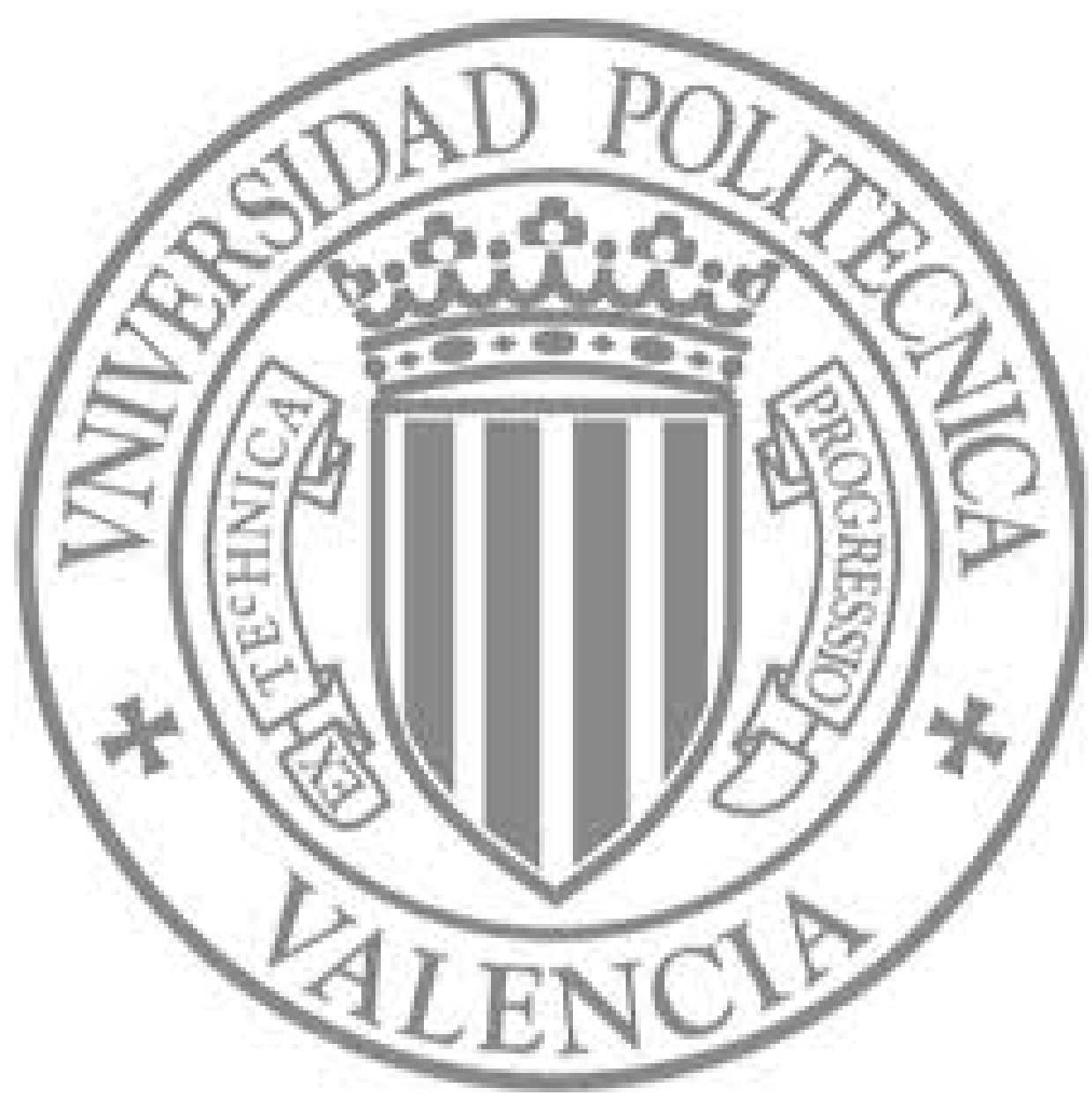

The final publication is available at

http://dx.doi.org/10.1016/j.jpcs.2012.04.002

Copyright Elsevier 


\title{
ZnO-based spinels grown by electrodeposition
}

\author{
M. Tortosa, * F. J. Manjón, M. Mollar, and B. Marí \\ Instituto de Diseño para la Fabricación y Producción Automatizada, Universitat Politècnica de \\ València, E-46022 Valencia, Spain.
}

\begin{abstract}
We report the synthesis of thin films of $\mathrm{ZnCO}_{2} \mathrm{O}_{4}$ and $\mathrm{ZnMn}_{2} \mathrm{O}_{4}$ spinels, as well as pure $\mathrm{Co}_{3} \mathrm{O}_{4}$ and $\mathrm{Mn}_{3} \mathrm{O}_{4}$ spinels, by means of electrodeposition. Spinel thin films have been analyzed by energy dispersive spectroscopy, X-ray diffraction, and Raman spectroscopy. We show that under certain deposition conditions, where the Co and $\mathrm{Mn}$ concentration in the films is above the solubility limit of these ions in the wurtzite structure, the initial wurtzite structure of Co- and Mn-doped $\mathrm{ZnO}$ develops into other compounds with spinel structure.
\end{abstract}

\section{Introduction}

Spinel oxides have a general formula $A^{\prime \prime} B^{\prime \prime \prime}{ }_{2} \mathrm{O}_{4}$ in which $A$ is a small divalent metal with tetrahedral coordination and $B$ is a large trivalent metal with octahedral coordination. It is known that spinels containing transition metal ions can act as efficient catalysts in a number of heterogeneous chemical processes, such as CO oxidation [1], catalytic combustion of hydrocarbons [2] or selective oxidation and reduction of several organic molecules [3-5]. They can also be used in Li-ion batteries $[6,7]$ and in gas sensors attending the growing demand for monitoring toxic and harmful gases [8].

Spinels are known to crystallize in either cubic $(\mathrm{Fd}-3 \mathrm{~m})$ or tetragonal ( $\left.14_{1} / \mathrm{amd}\right)$ structures. The tetragonal spinel structure results from a distortion of the cubic spinel structure due to the deformation of octahedra as a result of Jahn-Teller interactions. In particular, $\mathrm{CO}_{3} \mathrm{O}_{4}\left(\mathrm{Co}^{2+} \mathrm{Co}^{3+}{ }_{2} \mathrm{O}_{4}\right)$ is a pure cubic spinel [9] while $\mathrm{Mn}_{3} \mathrm{O}_{4}\left(\mathrm{Mn}^{2+} \mathrm{Mn}^{3+}{ }_{2} \mathrm{O}_{4}\right)$ is a tetragonal spinel due to the presence of Jahn-Teller $\mathrm{Mn}^{3+}$ ions in octahedral sites [10]. Spinels are complex structures because they have unoccupied cation sites in the unit cell that lead to intrinsic disorder, called inversion, in which cations at tetrahedral and octahedral sites interchange their respective positions. Few vibrational studies of the spinel structure are reported in the literature because $\mathrm{AO}_{4}$ and $\mathrm{BO}_{6}$ polyhedra are very interrelated and it is difficult to interpret vibrational spectra in terms of single contributions from tetrahedral or octahedral units.

The most general method for preparing oxide spinels is the ceramic process that requires the solid-state reaction of a mixed powder of the parent metal binary oxides at rather Corresponding author: martorjo@fis.upv.es 
high temperatures (usually higher than $1000^{\circ} \mathrm{C}$ ) during several days [11]. This method has several disadvantages such as inhomogeneities, lack of stoichiometric control and large particle size. These drawbacks can be avoided by synthesizing the materials using a solutionbased method [12] where the mixing of different metal species occurs at a molecular level leading to the formation of polycrystalline homogeneous particles. In particular, $\mathrm{ZnCo}_{2} \mathrm{O}_{4}$ has been recently prepared by several solution-based methods including coprecipitation [13], hydrothermal synthesis [14], calcination of hydroxide or carbonate precursor mixtures [15], electrophoretic deposition [16], and sol-gel method [17].

In this paper we report the deposition of thin films of spinel oxides by means of cathodic electrodeposition. This low-cost technique presents many advantages including the work at low temperatures (lower than $100^{\circ} \mathrm{C}$ ) and at atmospheric pressure, the high homogeneity of the deposited films, the possibility of depositing large areas, and the direct monitoring of the deposited charge in order to control the film thickness. The main drawback is that a conducting substrate is required; however, this is not a problem for some applications of $\mathrm{ZnCo}_{2} \mathrm{O}_{4}$ like the use of this material as an oxygen (or chlorine) evolution electrode in solution [18-20]. We characterize the spinel thin films by means of Raman spectroscopy while most of the literature devoted to the spinel oxides dealt essentially with the infrared spectra of $A^{\prime \prime} B^{\prime \prime \prime}{ }_{2} \mathrm{O}_{4}$ materials.

\section{Experimental details}

Ternary $\mathrm{Zn}_{x} \mathrm{Co}_{y} \mathrm{O}_{z}$ and $\mathrm{Zn}_{x} \mathrm{Mn}_{y} \mathrm{O}_{z}$ films have been growth by electrodeposition onto ITOcoated glass substrate. The experimental setup used is basically composed by a computercontrolled potentiostat/galvanostat and a classical three-electrode electrochemical cell filled with a solution containing $0.1 \mathrm{M} \mathrm{KClO}_{4}$ as supporting electrolyte and dissolved oxygen in a DMSO solution. $\mathrm{Zn}$ and $\mathrm{Co}$ chlorides are used as precursors: $\mathrm{ZnCl}_{2}, \mathrm{CoCl}_{2}$ and $\mathrm{MnCl}_{2}$ in different concentrations. $\mathrm{Pt}$ and $\mathrm{Ag} / \mathrm{AgCl}$ electrodes are used as counter electrode and reference electrode, respectively. The deposition potential was fixed at $-0.9 \mathrm{~V}$ and the solution temperatures are fixed at $900^{\circ} \mathrm{C}$ by a thermostat. This experimental setup has been previously used for the growth of wurzite-type ZnO-based ternary thin films with a high transparency and homogeneity [21-24]. The chemical composition has been determined by energy dispersive spectroscopy (EDS) and the structural characterization has been performed by $\mathrm{x}$-ray diffraction (XRD) measurements. Finally, joint chemical and structural information has been obtained from Raman scattering measurements. For EDS measurements, we have used a JEOL-JSM 6300 scanning electron microscope. For XRD measurements we have used a high resolution 
diffractometer system "Rigaku Ultima IV" using the copper anticathode $(\mathrm{Cu} K \alpha, \lambda=$ $1.542 \pm 0.002 \AA$ ). Finally, for Raman measurements we have used a LabRAM HR UV system with a Peltier-cooled CCD camera and with have excited with the $532 \mathrm{~nm}$ laser line. The resolution of Raman scattering measurements is better than $2 \mathrm{~cm}^{-1}$.

\section{Results and discussion}

Figure 1 shows the EDS results where the molar fraction $x(x=[M] /([M]+[Z n]))$ of the $M$ $(\mathrm{M}=\mathrm{Co}, \mathrm{Mn})$ ions in the $\mathrm{ZnO}$ films is represented as a function of the molar fraction of $\mathrm{M}$ in the initial solution. EDS results confirm that the $\mathrm{M}$ ions incorporate into the $\mathrm{ZnO}$ lattice. The different experimental points of Fig. 1 can be fitted with a Boltzmann function. Three different zones have been observed as a function of the initial molar fraction of the $M$ ions in the solution: the first zone (for values lower than 0.1 for $\mathrm{Co}$ and 0.3 for $\mathrm{Mn}$ ), where the curve has small slope; the second region (for values between 0.1 and 0.6 for Co and 0.3 and 0.6 for $\mathrm{Mn}$ ), where the curve has a big slope; and finally, the third part for values larger than 0.6 , where the curve has a small slope. The first zone is characterized by a small rate of incorporation of the $M$ ions into the wurtzite $\mathrm{ZnO}$ lattice and this leads to the formation of $\mathrm{M}$-doped $\mathrm{ZnO}$ with molar fractions in the films below $10 \%$. The second region, where the curve has a steep slope, is characterized by a strong incorporation of the $\mathrm{M}$ ions in the $\mathrm{ZnO}$ lattice well above the solubility limit of the $M$ ions in the wurtzite lattice and it is the zone where the formation of $\mathrm{ZnM}_{2} \mathrm{O}_{4}$ spinels takes place. Finally, the third part is a flat zone where the molar fraction of the $M$ ions in the films remains constant despite increasing the concentration in the initial solution. In this region occurs the formation of pure $\mathrm{M}_{3} \mathrm{O}_{4}$ spinels, as we will show in the following paragraphs.

Figures 2(a) and (b) show the XRD patterns for samples of $\mathrm{Zn}_{1-\mathrm{x}} \mathrm{M}_{\mathrm{x}} \mathrm{O}$ with different Co and $\mathrm{Mn}$ molar fractions in the films, respectively. The peaks with the symbol $\left({ }^{*}\right)$ belong to the ITO substrate. In both figures the peaks placed in $34.42^{\circ}$ and $36.25^{\circ}$ correspond to crystallographic directions (002) and (101) of the $\mathrm{ZnO}$ wurtzite structure. Our $\mathrm{Zn}_{1-x} \mathrm{M}_{x} \mathrm{O}$ thin films grow preferentially along the (002) direction but this preferential direction of growth is reduced with increasing $\mathrm{M}$ concentration and at molar fractions above $10 \%$ the (101) direction is preferred. The wurtzite diffraction peaks disappear of the XRD patterns for molar fractions larger than $\mathbf{2 0 \%}$ for Co and larger $30 \%$ for $\mathrm{Mn}$ in the films. It is rather curious beyond these molar fractions no XRD peaks are observed from the films even at the highest $M$ 
concentrations. Therefore, this result suggests that our films are amorphous or strongly disordered. Consequently, we have resorted to Raman spectroscopy to determine the possibly structure of the thin films with high $\mathrm{M}$ concentrations.

According to group theory, cubic spinels have the following phonon modes at the $\Gamma$ point [25]

$$
\Gamma=A_{1 g}(R)+E_{g}(R)+3 T_{2 g}(R)+5 T_{1 u}(I R)+T_{1 g}+2 A_{2 u}+2 E_{u}+2 T_{2 u}
$$

where R and IR corresponds to Raman- and infrared-active modes, respectively, where one triply degenerated $T_{1 u}$ correspond to acoustic modes, and $T_{1 g}, E_{u}, A_{2 u}$, and $T_{2 u}$ are silent modes. Therefore, five Raman-active modes are expected in this structure. Figure $\mathbf{3}$ (a) and (b) show the results of different Raman spectra for samples with high Co and Mn concentrations, respectively. Figure 3(a) exhibits two different types of Raman spectra that can be related to two different compounds, namely the $\mathrm{ZnCo}_{2} \mathrm{O}_{4}$ and the $\mathrm{Co}_{3} \mathrm{O}_{4}$ spinels. For Co molar fractions in the films higher than $90 \%$ five narrow Raman modes are appreciated whose frequencies match with the Raman-active modes of the pure $\mathrm{Co}_{3} \mathrm{O}_{4}$ spinel as reported in the literature [26] (see values in Table 1). The small frequency changes between our samples and those reported in the literature are probably due to the $\mathrm{Zn}$ impurities present in our samples.

For molar fractions of Co below $90 \%$ the Raman spectra is formally identical to the $\mathrm{ZnCO}_{2} \mathrm{O}_{4}$ films of spinel structure already reported in the literature [27] (see Table 1). It can be observed that more than five Raman-active modes appear in the spectra. We think that the additional Raman modes (peaks marked with the asterisk in Fig. 3(a) and Table 1) occur because of the inversion of spinels. The mixture of cations in both crystal positions can produce the splitting of Raman modes to higher or lower frequency depending on the contribution of the cations to each Raman mode and the mass of each cation. In particular, the Raman $\mathrm{T}_{2 \mathrm{~g}}$ mode at lowest frequency around $193 \mathrm{~cm}^{-1}$ in $\mathrm{Co}_{3} \mathrm{O}_{4}$ splits into two modes at 185 and $204 \mathrm{~cm}^{-1}$ in $\mathrm{ZnCo}_{2} \mathrm{O}_{4}$. The mode at $193 \mathrm{~cm}^{-1}$ in $\mathrm{Co}_{3} \mathrm{O}_{4}$ is a stretching mode in $\mathrm{AB}_{2} \mathrm{O}_{4}$ spinels related to A-O vibrations, and therefore is mainly contributed by Co ions in tetrahedral position in $\mathrm{CO}_{3} \mathrm{O}_{4}$ [28]. In this sense, one can understand that the mode at $185 \mathrm{~cm}^{-1}$ in $\mathrm{ZnCo}_{2} \mathrm{O}_{4}$ could be due to the occupation of tetrahedral sites by $Z n$, which has a slightly larger mass than Co, and that the small broad band around $204 \mathrm{~cm}^{-1}$ mode could be a signature of residual Co atoms in the tetrahedral sites in partially-inversed $\mathrm{ZnCo}_{2} \mathrm{O}_{4}$. Contrarily, the Raman $\mathrm{A}_{1 \mathrm{~g}}$ mode at highest frequency around $682 \mathrm{~cm}^{-1}$ in $\mathrm{CO}_{3} \mathrm{O}_{4}$ splits into two modes at 661 and $686 \mathrm{~cm}^{-1}$ in $\mathrm{ZnCo}_{2} \mathrm{O}_{4}$. Since the $\mathrm{A}_{1 \mathrm{~g}}$ mode is a $\mathrm{B}-\mathrm{O}$ stretching mode in $\mathrm{AB}_{2} \mathrm{O}_{4}$ spinels which is mainly 
contributed by the $\mathrm{Co}$ in octahedral coordination in $\mathrm{CO}_{3} \mathrm{O}_{4}$ [28], the mode at $686 \mathrm{~cm}^{-1}$ in $\mathrm{ZnCo}_{2} \mathrm{O}_{4}$ seems to indicate the presence of $\mathrm{Co}$ in octahedral coordination while the broad band at $661 \mathrm{~cm}^{-1}$ would evidence the presence of a considerable amount of $\mathrm{Zn}$ ions in octahedral coordination.

As already commented, manganese oxide spinels $\left(\mathrm{AMn}_{2} \mathrm{O}_{4}\right)$ typically have tetragonal spinel structure [29]. According to group theory, tetragonal spinels have the following phonon modes at the $\Gamma$ point [30]

$$
\Gamma=2 A_{1 g}(R)+3 \mathrm{~B}_{1 g}(R)+\mathrm{B}_{2 g}(R)+4 E_{g}(R)+5 A_{2 u}(\mathrm{IR})+7 E_{u}(\mathrm{IR})+2 A_{1 u}+A_{2 g}+2 B_{2 u}
$$

where R and IR corresponds to Raman- and infrared-active modes, respectively, where one $A_{2 u}$ and one double degenerate $E_{u}$ correspond to acoustic modes, and where $A_{1 u}, A_{2 g}$, and $B_{2 u}$ are silent modes. Therefore, ten Raman-active modes are expected in this structure. Figure $\mathbf{3}(\mathbf{b})$ displays the Raman spectra for different samples with high Mn concentrations. It is observed that the Raman spectra can be classified again into two different classes. The first type of Raman spectra occurs for molar fractions of $\mathrm{Mn}$ between $66 \%$ and $78 \%$ and they correspond to a mixed spinel structure of $\mathrm{ZnMn}_{2} \mathrm{O}_{4}$ with tetragonal symmetry since similar bands to ours have been reported by Malavasi et al. [28] which have been summarized in Table 2. Black upward arrows in Fig. 3(b) mark the frequencies of the Raman modes of $\mathrm{ZnMn}_{2} \mathrm{O}_{4}$ reported by Malavasi et al. for comparison with our spectra. In order to show how we have obtained the frequencies reported in Table 2 for $\mathrm{ZnMn}_{2} \mathrm{O}_{4}$ we show in Figure 4 (a) a decomposition of the Raman spectrum of $\mathrm{ZnMn}_{2} \mathrm{O}_{4}$, assuming that this stoichiometry is close to our sample with molar fraction $x=0.66$. It can be observed that we have fitted up to 8 peaks out of the 10 allowed Raman modes, whose frequencies compare reasonably with those of the five peaks reported in Ref. 28. Note that the frequencies of our $\mathrm{ZnMn}_{2} \mathrm{O}_{4}$ samples can be considerably affected by lack of stoichiometry. In fact, it can be observed that there is a shift of the Raman modes for higher $\mathrm{Mn}$ molar fractions than $\mathrm{x}=0.66$ and that our frequencies are shifted with respect to those reported by Malavasi et al. [28]. These results suggest that our samples with $x>0.66$ have an excess of $\mathrm{Mn}$ with respect to the $\mathrm{ZnMn}_{2} \mathrm{O}_{4}$ stoichiometry.

The second class of Raman spectra correspond to the three samples with Mn molar fraction above $x=0.85$ in the films where the Raman spectrum is dominated by two broad bands. We have ascribed this sample to the spinel $\mathrm{Mn}_{3} \mathrm{O}_{4}$ whose frequencies are summarized in Table 2 and compared to those present in the literature. In order to show how we have 
obtained the frequencies reported in Table 2 for $\mathrm{Mn}_{3} \mathrm{O}_{4}$ we show in Figure 4 (b) a decomposition of the Raman spectrum of $\mathrm{Mn}_{3} \mathrm{O}_{4}$ assuming that this stoichiometry is close to our sample with $x=0.95$. We have fitted up to 7 peaks out of the 10 allowed Raman modes, whose frequencies compare reasonably with those of the five peaks reported in Ref. $\mathbf{2 8}$ for $\mathrm{Mn}_{3} \mathrm{O}_{4}$. In Fig. 3(b), we have marked with red downward arrows the frequencies of the stronger bands of the $\mathrm{Mn}_{3} \mathrm{O}_{4}$ spinel reported by Lutz et al. and Malavasi et al. [28,31]. The frequencies of the Raman bands observed in our films with the highest $\mathrm{Mn}$ concentration match reasonably well with the frequencies of the Raman bands of the observed by other authors (see Table 2). Note that in our $\mathrm{Mn}_{3} \mathrm{O}_{4}$ films the fourth and five peaks reported by Malavasi et al. are observed as a broad band ranging from 250 to $350 \mathrm{~cm}^{-1}$ where three Gaussians can be fitted around 278, 301, and $334 \mathrm{~cm}^{-1}$. Similarly, the broad band ranging from 520 to $700 \mathrm{~cm}^{-1}$ in our films has been fitted to two Gaussian profiles, being the stronger in intensity at a frequency of $645 \mathrm{~cm}^{-1}$, which is close to the value reported for the strongest Raman peak of $\mathrm{Mn}_{3} \mathrm{O}_{4}\left(660 \mathrm{~cm}^{-1}\right)$.

Finally, we want to stress that the strongly broadened Raman bands of the films with the two highest Mn concentrations suggest the formation of strongly deformed or amorphous structures of tetragonal $\mathrm{Mn}_{3} \mathrm{O}_{4}$ spinel as compared to the narrow peaks reported in Ref. 28 . However, we are confident that our films with the highest Mn concentrations correspond to the $\mathrm{Mn}_{3} \mathrm{O}_{4}$ spinel because the magnetisation curves that have been measured in our previous work exhibit the same magnetisation properties than $\mathrm{Mn}_{3} \mathrm{O}_{4}$ spinel [32].

\section{Conclusions}

Spinel-type $\mathrm{ZnM}_{2} \mathrm{O}_{4}$ and $\mathrm{M}_{3} \mathrm{O}_{4} \quad(\mathrm{M}=\mathrm{Mn}, \mathrm{Co})$ thin films have been obtained by electrodeposition with high transparency and homogeneity. EDS results confirm the incorporation of the Co or $\mathrm{Mn}$ ions in the $\mathrm{ZnO}$ lattice. Up to $20 \%$ at. Co and $10 \%$ at. $\mathrm{Mn}$ can be incorporated into the wurtzite $\mathrm{ZnO}$ lattice, whereas above those limits spinel-type compounds are formed as evidenced by Raman scattering measurements. At intermediate $\mathrm{M}$ molar fractions in the initial solution spinel-type $\mathrm{ZnM}_{2} \mathrm{O}_{4}$ is formed, while at high $\mathrm{M}$ concentrations pure $\mathrm{M}_{3} \mathrm{O}_{4}$ spinel is formed. The narrow Raman peaks of $\mathrm{Co}_{3} \mathrm{O}_{4}$ indicate that this pure spinel has rather good crystal quality while the broad Raman peaks of $\mathrm{Mn}_{3} \mathrm{O}_{4}$ suggest that this pure spinel has a bad crystal quality. 


\section{Acknowledgements}

The authors are grateful to Ministerio de Ciencia e Innovación of Spain (MICINN) under the National Program of Materials (MAT2007-65990-C03-02 and MAT2010-21270-C04-04) and the Consolider-Ingenio 2010 Program (MALTA CSD2007-0045).

\section{References}

[1] J. Ghose, K.S.R.C. Murthy, J. Catal. 162, 359 (1996).

[2] N. Guilhaume, M. Primet, J. Chem. Soc. Faraday Trans. 90, 1541 (1994).

[3] B.L. Yang, D.S. Chen, S.B. Lee, Appl. Catal. 70, 161 (1991).

[4] J.P. Jacobs, A. Maltha, J.G. H. Reinthjes, J. Drimal, V. Ponec, H.H. Brongersma, J. Catal. 147, 294 (1994).

[5] J. Sloczynski, J. Ziólkovski, B. Grzybowska, R. Grabowski, D. Jachewicz, K. Wcislo, and L. Gengembre, J. Catal. 187, 410 (1999).

[6] C. Ai, M. Yin, C. Wang, and J. Sun, J. Mat. Sci. 39, 1077 (2004).

[7] Y. Sharma, N. Sharma, G.V. Subba Rao, and B.V.R. Chowdari, Adv. Funct. Mat. 17, 2855 (2007).

[8] X. Niu, W.P. Du, and W.M. Du, Sensors \& Actuators B 99, 405 (2004).

[9] W.M. Shaheen and A.A. Ali, Materials Research Bulletin 36, 1703 (2001).

[10] D. Jarosch, Mineralogy and Petrology 37, 15 (1987).

[11] C. Otero Areán, M. Peñarroya Mentruit, A.J. López López, J.B. Barra, Phys. Eng. Aspects 180, 253 (2001).

[12] A. Manthiram and J. Kim, Chem. Mater. 10, 2895 (1998).

[13] K.L. Zhang, J.B. Yuan, G.F. Zhu, Q.C. Zhang, J.T. Tang, J. Wuhan Univ. (Nat. Sci. Ed.) 4, 428 (1997).

[14] A.G. Shi, A.H. Hang, J. Fang, J.S. Chi, M.M. Wu, Chin. J. Inorg. Chem. Ind. 5, 14 (2001).

[15] K.J. Omata, T.K.S. Takada, S.J. Kasahara, M.N.Y.S. Yamada, Appl. Catal. A:Gen. 146, 255 (1996).

[16] B. Chi, J. Li, X. Yang, H. Lin, and N. Wang, Electrochim. Acta 50, 2059 (2005).

[17] X. Wei, D. Chen, and W. Tang, Mat. Chem. Phys. 103, 54 (2007).

[18] S. Trasatti, G. Lodi in: S. Trasatti (Ed.), Electrodes of Conductive Metallic Oxides, Part A, Elsevier, Amsterdam, 1980.

[19] P. Rasiyah, A.C.C. Tseung, D.B. Hibbert, J. Electrochem. Soc.: Electrochem. Sci. Techhol. 129, 1724 (1982).

[20] R.N. Singh, J.-F. Koenig, G. Poillerat, P. Chartier, J. Electrochem. Soc. 137, 1408 (1990).

[21] M. Tortosa, M. Mollar, and B. Marí, J. Cryst. Growth 304, 97 (2007).

[22] M. Tortosa, M. Mollar, and B. Marí, Physica Status Solidi (C) 5, 3467 (2008).

[23] B. Marí, J. Cembrero, M. Mollar, and M. Tortosa, Physica Status Solidi (C) 5, 555 (2008).

[24] M. Tortosa, M. Mollar, B. Marí, and F. Lloret, J. Appl. Phys. 104, 033901 (2008).

[25] A. Chopelas and A. Hofmeister, Phys. Chem. Miner. 18, 279 (1991).

[26] V.G. Hadjiev, M.N. Iliev, and I.V. Vergilov, J. Phys. C: Solid State Phys. 21, 199 (1988). 
[27] K. Samanta, P. Bhattacharya, R.S. Katiyar, W. Iwamoto, P.G. Pagliuso, and C. Rettori, Phys. Rev. B 73, 245213 (2006).

[28] L. Malavasi, P. Galinetto, M.C. Mozzati, C.B. Azzoni, and G. Flor, Phys. Chem. Chem. Phys. 4, 3876 (2002).

[29] M. Nogues and P. Poix, Ann. Chim. (Paris) 1972, 301 (1972).

[30] Bilbao Crystallographic Server, http://www.cryst.ehu.es

[31] H.D. Lutz, B. Müller, and H.J. Steiner, J. Solid State Chem. 90, 54 (1991).

[32] M. Mollar, M. Tortosa, R. Casasús, B. Marí, Microelectronics Journal 40, 276-279 (2009). 
Table 1 Frequencies and symmetries of Raman modes observed in $\mathrm{ZnCo}_{2} \mathrm{O}_{4}(\mathrm{x}=0.58)$ thin films compared to those reported in the literature (Ref. 27) and of $\mathrm{CO}_{3} \mathrm{O}_{4}(\mathrm{x}=0.99)$ thin films compared to those reported in the literature (Ref. 5).

\begin{tabular}{|c|c|c|c|c|}
\hline Phonon symmetry & $\begin{array}{l}\text { Frequency }\left(\mathrm{cm}^{-1}\right) \\
\mathrm{ZnCo}_{2} \mathrm{O}_{4}(\mathrm{x}=0.58)\end{array}$ & $\begin{array}{l}\text { Frequency }\left(\mathrm{cm}^{-1}\right) \\
\mathrm{ZnCo}_{2} \mathrm{O}_{4} \text { (Ref. 27) }\end{array}$ & $\begin{array}{c}\text { Frequency }\left(\mathrm{cm}^{-1}\right) \\
\mathrm{Co}_{3} \mathrm{O}_{4}(\mathrm{x}=0.99)\end{array}$ & $\begin{array}{c}\text { Frequency }\left(\mathrm{cm}^{-1}\right) \\
\mathrm{Co}_{3} \mathrm{O}_{4} \text { (Ref. 5) }\end{array}$ \\
\hline$\overline{T_{2 g}}$ & 193 & 193 & 193 & 194.4 \\
\hline $\mathbf{E}_{\mathrm{g}}$ & 476 & 476 & 476 & 482.4 \\
\hline $\mathbf{T}_{2 g}$ & 517 & 517 & 517 & 521.6 \\
\hline $\mathbf{T}_{2 \mathrm{~g}}$ & 615 & 615 & 615 & 618.4 \\
\hline$A_{1 g}$ & 683 & 683 & 683 & 691.0 \\
\hline * & 204 & 200 & & \\
\hline$*$ & 661 & 660 & & \\
\hline
\end{tabular}


Table 2 Frequencies and symmetries of Raman modes observed in $\mathrm{ZnMn}_{2} \mathrm{O}_{4}(\mathrm{x}=0.66)$ and of $\mathrm{Mn}_{3} \mathrm{O}_{4}(\mathrm{x}=0.95)$ thin films compared to those reported in the literature (Ref. 28).

\begin{tabular}{|c|c|c|c|c|}
\hline Phonon mode & $\begin{array}{c}\text { Frequency }\left(\mathrm{cm}^{-1}\right) \\
\mathrm{ZnMn}_{2} \mathrm{O}_{4}(\mathrm{x}=0.66)\end{array}$ & $\begin{array}{c}\text { Frequency }\left(\mathrm{cm}^{-1}\right) \\
\left.\mathrm{ZnMn}_{2} \mathrm{O}_{4} \text { (Ref. } 28\right)\end{array}$ & $\begin{array}{c}\text { Frequency }\left(\mathrm{cm}^{-1}\right) \\
\mathrm{Mn}_{3} \mathrm{O}_{4}(\mathrm{x}=0.95)\end{array}$ & $\begin{array}{c}\text { Frequency }\left(\mathrm{cm}^{-1}\right) \\
\mathrm{Mn}_{3} \mathrm{O}_{4} \text { (Ref. 28) }\end{array}$ \\
\hline Peak 1 & 276 & 300.2 & 278 & \\
\hline Peak 2 & 316 & 320.5 & 301 & 290 \\
\hline Peak 3 & 320 & & 334 & 319 \\
\hline Peak 4 & 369 & 381.9 & 405 & 374 \\
\hline Peak 5 & 463 & 475.5 & 474 & 479 \\
\hline Peak 6 & 563 & & 599 & \\
\hline Peak 7 & 630 & & & \\
\hline Peak 8 & 663 & 677.6 & 645 & 660 \\
\hline
\end{tabular}




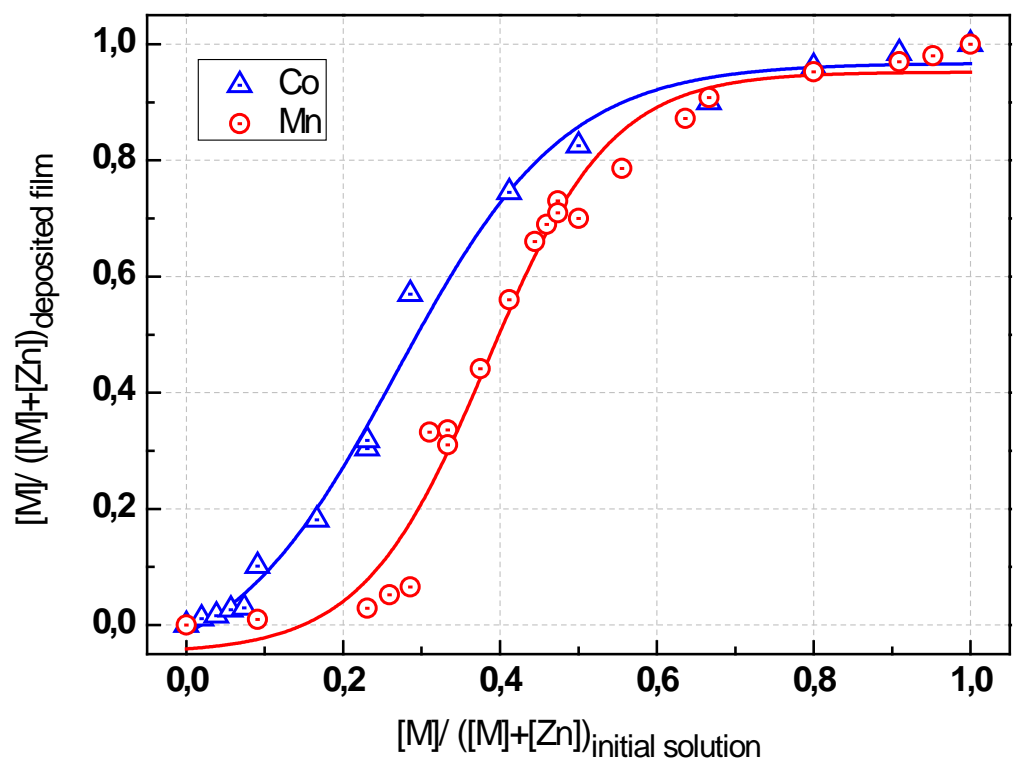

Figure 1 Molar fraction $\mathrm{x}=[\mathrm{M}] /([\mathrm{M}]+[\mathrm{Zn}])$ in the deposited film as a function of the molar fraction in the initial solution. 
(a)

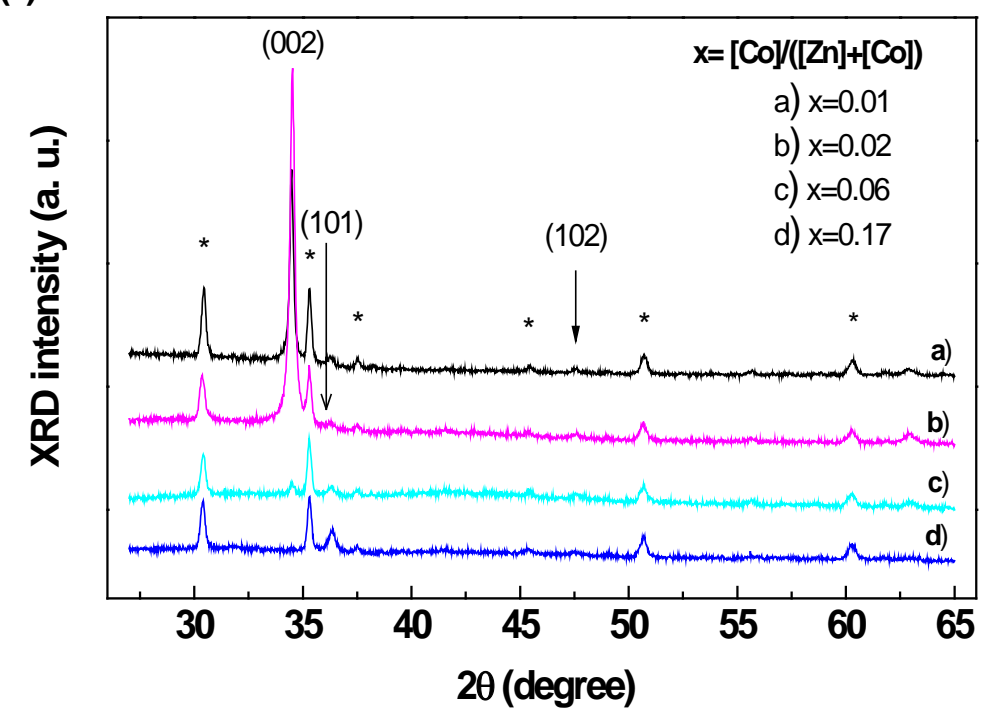

(b)

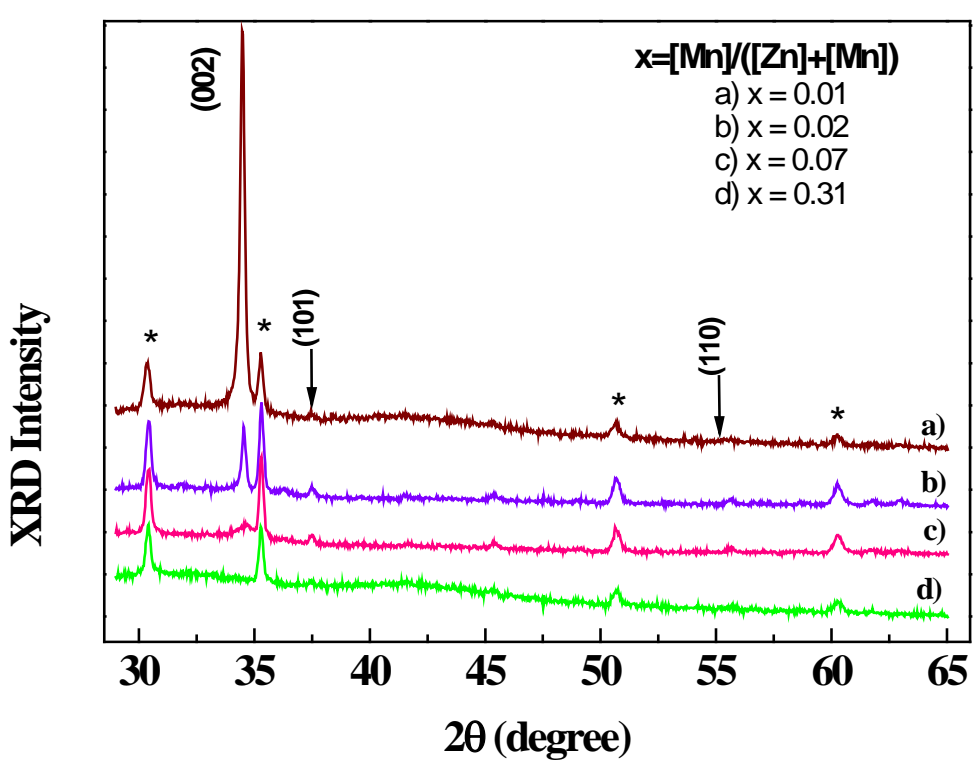

Figure 2 (a) XRD scan diagram of $\mathrm{Zn}_{1-x} \mathrm{Co}_{x} \mathrm{O}$ films for different $\mathrm{Co}$ molar fractions, (b) XRD scan diagram of $\mathrm{Zn}_{1-\mathrm{x}} \mathrm{Mn}_{\mathrm{x}} \mathrm{O}$ films for different $\mathrm{Mn}$ molar fractions. Asterisks correspond to XRD peaks of ITO substrate. 

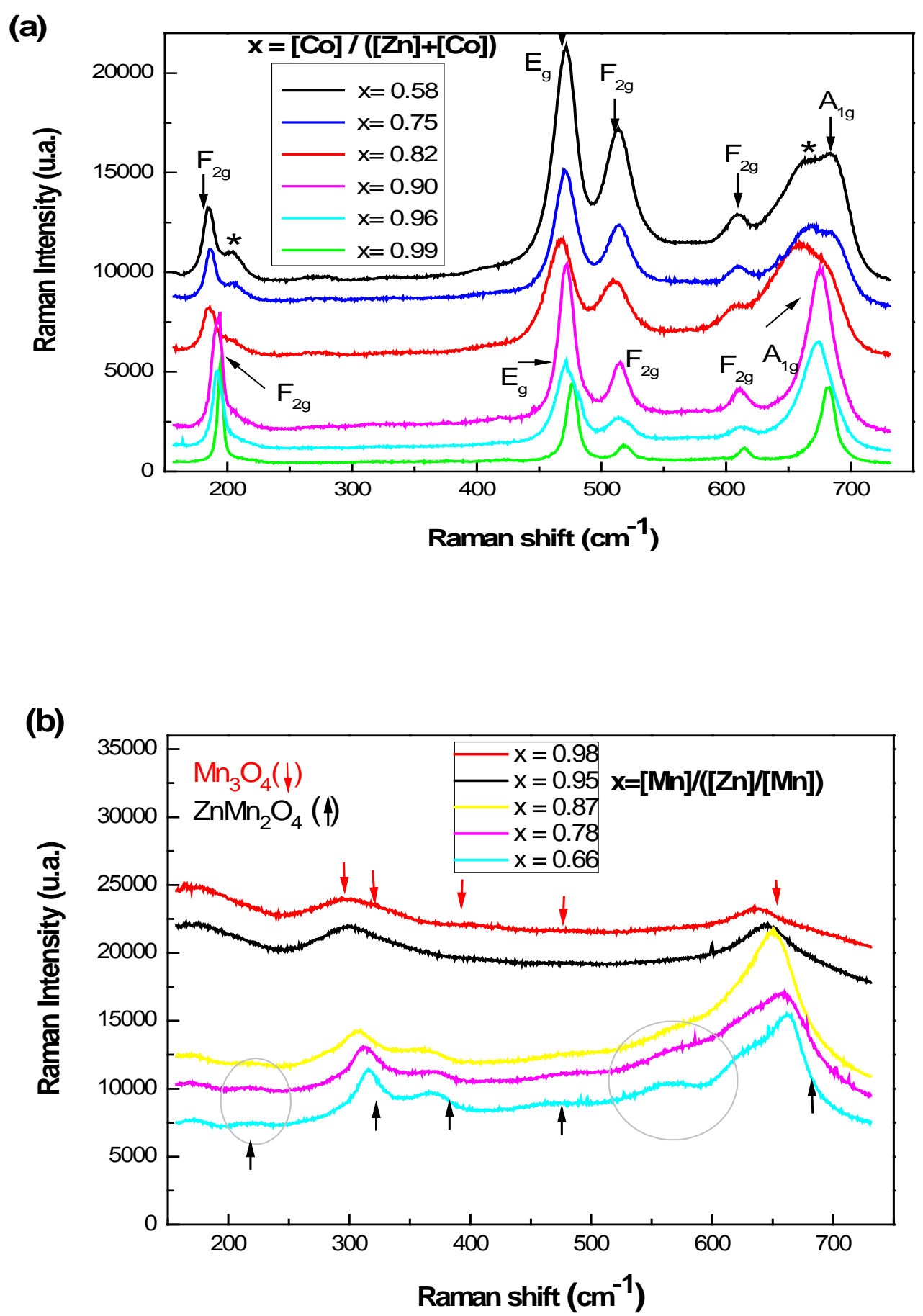

Figure 3. (a) Raman spectra of thin films with different molar fractions of Co in the films. (b) Raman spectra of thin films for different molar fractions of $\mathrm{Mn}$ in the films. 
(a)

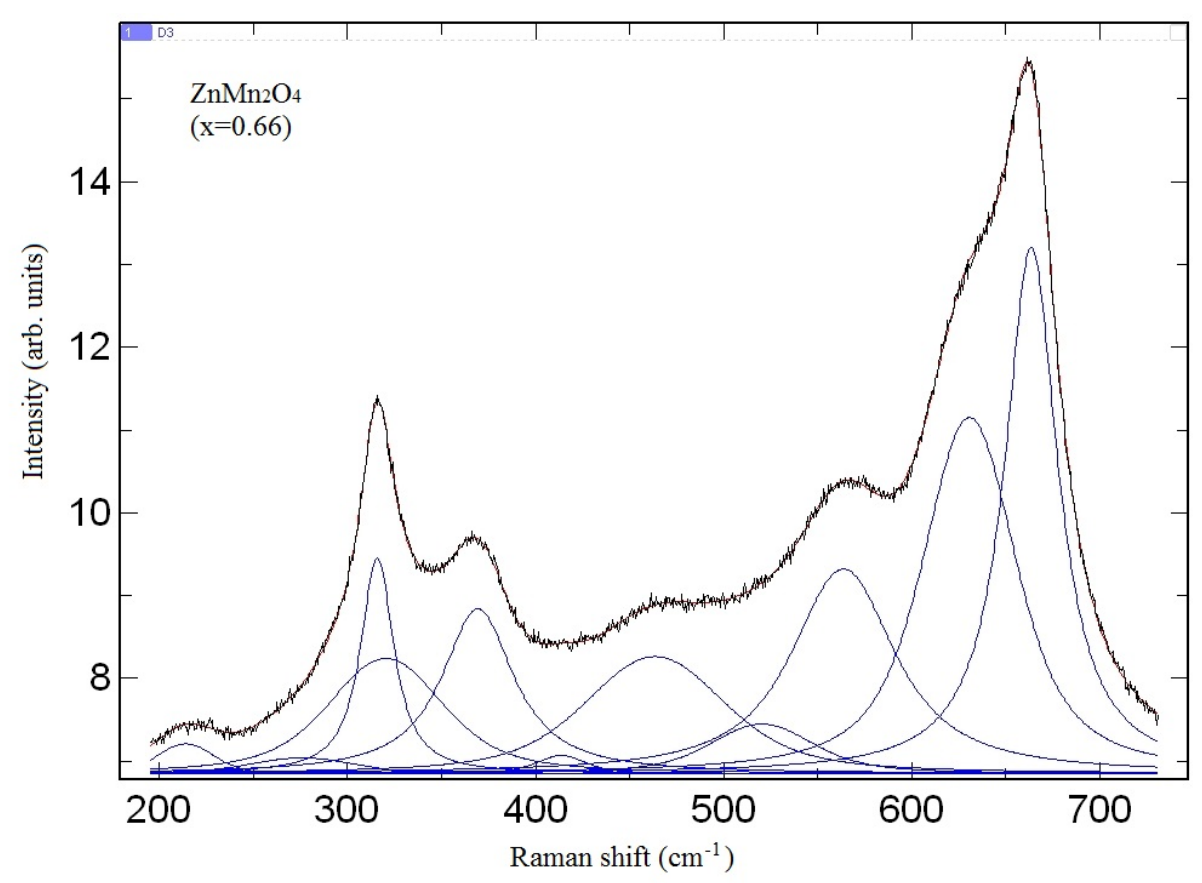

(b)

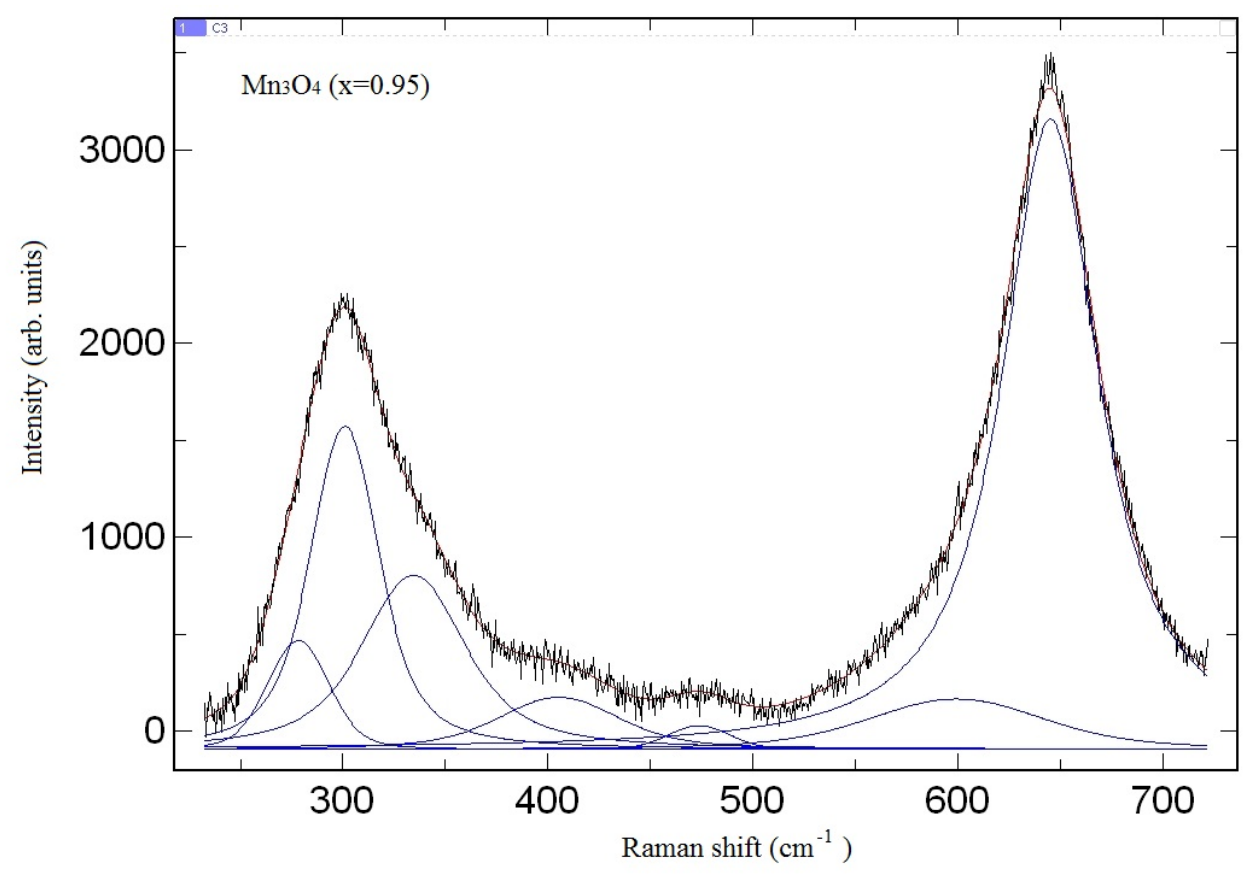

Figure 4. (a) Raman spectra of a thin film with a $\mathrm{Mn}$ molar fraction of $0.66\left(\mathrm{ZnMn}_{2} \mathrm{O}_{4}\right)$ decomposed into Gaussian profiles. (b) Raman spectra of a thin film with a Mn molar fraction of $0.95\left(\mathrm{Mn}_{3} \mathrm{O}_{4}\right)$ decomposed into Gaussian profiles. 